\title{
Implementation Of Leadership Values in Pancasila Paradigm as Character Building Values
}

\author{
Zulfikar Putra ${ }^{1}$, Farid Wajdi ${ }^{2}$ \\ Program Studi PPKn FKIP Universitas Sembilanbelas November, Kolaka, Indonesia ${ }^{1,2}$ \\ zulfikarputra2016@gmail.com¹, wajdikf83@usn.ac.id²
}

\section{Article History}

accepted 24/03/2021

$$
\text { approved 10/04/2021 }
$$

published 20/04/2021

\begin{abstract}
The purpose of this study was to determine the implementation of leadership values in the Pancasila paradigm as a character-building value. This research uses descriptive qualitative type and literature study by applying the technique of observation, documentation, and interviews. The data analysis technique is done by categorizing and classifying based on the logical analysis, then interpreted in the context of the whole research problem. The findings of the research show that students of basic leadership training do not understand the values of leadership in an applicative manner, this can be seen by the incomplete understanding of leaders and leadership. This research is expected that students are able to implement leadership values in the context of the Pancasila paradigm through character building in everyday life.
\end{abstract}

Keywords: leadership, Pancasila paradigm, character-building values

\section{Abstrak}

Tujuan penelitian ini adalah untuk mengetahui implementasi nilai-nilai kepemimpinan dalam paradigma pancasila sebagai nilai character building. Penelitian menggunakan jenis kualitatif deskriptif dan studi pustaka dengan menerapkan teknik observasi, dokumentasi dan wawancara. Teknik anlisis data dilakukan dengan cara mengkategorikan dan mengklasifikasikan berdasarkan analisis secara logis, kemudian ditafsirkan dalam konteks keseluruhan masalah penelitian. Temuan hasil penelitian, bahwa mahasiswa pelatihan dasar kepemimpinan belum memahami nilai-nilai kepemimpinan secara aplikatif, hal tersebut dapat dilihat dengan belum utuhnya pemahaman tentang pemimpin dan kepemimpinan. Penelitian ini diharapkan mahasiswa mampu mengimplementasikan nilai-nilai kepemimpinan dalam konteks paradigma pancasila melalui character building dalam kehidupan sehari-hari.

Kata kunci: kepemimpinan, paradigma pancasila, nilai character building

Social, Humanities, and Education Studies (SHEs): Conference Series https://jurnal.uns.ac.id/shes

p-ISSN 2620-9284

e-ISSN 2620-9292 


\section{PENDAHULUAN}

Manusia sebagai salah satu makhluk ciptaan Tuhan, keberadaannya diberikan tanggung jawab oleh Tuhan untuk mengelola dan mengatur alam dunia sesuai dengan perintah Sang Maha Pencipta. Kemudian dengan akal pikirannya, manusia harus mampu menciptakan suasana harmonis dan selaras agar interaksi sosial masyarakat berjalan dengan baik dan seimbang. Keadaan demikian dibutuhkan figur seorang manusia (pemimpin) yang memiliki pengetahuan, pendidikan, keterampilan, dan kecerdasan dalam mengelola alam dunia ini. Dalam ajaran Islam dikatakan, bahwa Allah menjadikan manusia sebagai seorang pemimpin di muka bumi sebagai wakil Tuhan dalam mengatur alam dunia ini dan manusia diciptakan untuk mengabdikan dirinya kepada Tuhan. (QS. Al-Baqarah: 30 dan QS. adz-Dzariyat: 56). Dengan demikian, manusia merupakan wakil Tuhan yang diberikan amanah dalam mengelola dan mengatur dunia yang senantiasa mengalami perubahan dan perkembangan agar terciptanya keadaan yang baik dan seimbang. Pembentukan sifat kepemimpinan dalam diri manusia merupakan kehendak Tuhan dari hasil ajaran alamiah sejak manusia belum dilahirkan.

Perubahan dan perkembangan yang terjadi di dunia, sangat dibutuhkan sosok manusia sebagai wakil Tuhan (kepemimpinan) yang baik dan mampu mengemban amanah yang terwejantahkan dengan perilaku berdasarkan nilai-nilai yang terdapat dalam nilai budaya, nilai agama, dan nilai kebangsaan yang bersumber dari kristalisasi nilai-nilai tersebut, yaitu pancasila yang merupakan ideologi dan falsafah kehidupan warga negara Republik Indonesia. Berdasarkan Keputusan Presiden Republik Indonesia nomor 10 tahun 1979 tentang Badan Pembinaan Pendidikan Pelaksanaan Pedoman Penghayatan dan Pengamalan Pancasila pada bagian menimbang point a menyebutkan, pedoman penghayatan dan pengamalan Pancasila adalah sarana untuk mewujudkan kesatuan bahasa, kesatuan pandangan dan kesatuan gerak bagi bangsa Indonesia dalam usaha menghayati dan mengamalkan Pancasila dalam kehidupannya sehari-hari (Indonesia 1979).

Nilai-nilai yang terdapat dalam pancasila diupayakan sebagai tali pemersatu persaudaraan kebangsaan yang memiliki beragam budaya, agama, suku, dan bahasa. (Putra 2018), pendidikan Pancasila adalah program pendidikan yang berisi nilai-nilai luhur bangsa yang memiliki tujuan untuk membentuk sikap positif manusia sesuai dengan nilai-nilai yang terkandung dalam Pancasila. (Z. Putra 2021), pancasila merupakan landasan ideologi kebangsaan Negara Republik Indonesia. Indonesia sebagai negara majemuk akan budaya, suku (etnis), bahasa, dan agama, mampu mempertahankan kedaulatan negara kesatuan republik Indonesia dengan falsafah kebangsaan, yakni Pancasila sebagai sebuah ideologi kewarganegaraan Indonesia.

Dewasa ini, peran kepemimpinan sangat dibutuhkan dalam menjaga stabilitas nasional. Fenomena yang terjadi, semakin meningkatkan angka korupsi dana bantuan sosial (BANSOS), indikasi adanya pertikaian sesama anak bangsa, yang pro dan kontra terhadap kebijakan pemerintah serta beberapa peristiwa lainnya yang mengancam disintegrasi bangsa. Padahal, penanaman serta pembentukan karakter pun senantiasa dilakukan, baik dalam lingkungan keluarga, masyarakat dan bernegara maupun dalam satuan pendidikan.

Karakter adalah watak-sifat-tabiat yang ada dalam diri setiap individu dan masing-masing individu memiliki karakter yang berbeda-beda. Menurut Ki Hadjar Dewantara selaku tokoh Bapak Pendidikan Nasional Indonesia mengatakan, Karakter (watak) adalah paduan daripada segala tabiat manusia yang bersifat tetap, sehingga menjadi tanda yang khusus untuk membedakan orang yang satu dengan yang lain. Lebih lanjut beliau mengatakan, pendidikan karakter pada dasarnya untuk mendorong jiwa anak-anak lahir dan batin dari sifat kodratinya menuju ke arah peradaban yang manusiawi dan untuk melaksanakan pendidikan karakter maka harus bersikap ngertingroso-nglakoni yang artinya menyadari, menginsyafi, dan melakukan. Pendidikan 
karakter adalah proses yang terjadi secara terus menerus dan mewujudkan penciptaan manusia yang memiliki nilai-nilai budaya bangsa yang kuat (Dewantara 2013). Istilah karakter dapat diartikan sebagai sistem daya juang (daya dorong, daya gerak, dan gaya hidup) yang berisikan tata nilai kebajikan dan moral yang berpatri dalam diri manusia (Putra 2018).

Pendidikan karakter adalah sebagai cara berpikir dan berprilaku yang menjadi ciri khas setiap individu untuk hidup dan bekerjasama, baik dalam lingkungan keluarga, masyarakat, bangsa, dan negara (Wajdi 2020). Secara umum pendidikan sekurangkurangnya memiliki empat fungsi, yaitu transfer ilmu, konservasi dan pengembangan ilmu, penguasaan life skill dan teknologi, serta membangun karakter (character building) (Putra 2018). Hakikat pendidikan karakter dalam perspektif pendidikan Indonesia adalah pendidikan nilai, yang merupakan hasil dari proses kulturisasi pendidikan nilai-nilai luhur yang tercermin dalam budaya bangsa Indonesia guna membentuk sumber daya manusia Indonesia yang berkualitas (F. Wajdi 2021). Pembentukan karakter (character building) merupakan sebuah proses penanaman berupa nilai-nilai baik sebagai cerminan perilaku seseorang. Dalam perspektif pendidikan, character building merupakan proses pembinaan dalam memperbaiki atau membentuk tabiat-watak-sifat kejiwaan manusia (masyarakat) berdasarkan nilai-nilai yang terkandung dalam pancasila. Perubahan dalam character building yang positif memantapkan nilai-nilai Pancasila sebagai falsafah hidup bangsa dalam mengembangkan kehidupan nasional yang lebih berkualitas.

Pancasila merupakan falsafah bangsa Indonesia. Nilai-nilai yang terkandung dalam Pancasila menjadi pedoman dalam kehidupan bermasyarakat, berbangsa, dan bernegara. Inti sila-sila Pancasila menjadi norma dan tolak ukur bagi kegiatan kenegaraan, kemasyarakatan, dan perseorangan. Perbuatan manusia dianggap bermoral (beretika) atau mempunyai nilai etik, jika memenuhi tolak ukur Pancasila. Kepemimpinan harus mengacu pada nilai-nilai yang terkandung dalam Pancasila (Gunawan 2016).

Kepemimpinan merupakan aktivitas seorang pemimpin dalam memberikan pengaruh baik bagi sekumpulan orang dalam memenuhi tujuannya. Seorang pemimpin dalam menjalankan kepemimpinannya dibutuhkan kemampuan (life skill) yang melahirkan nilai-nilai. Nilai merupakan konsepsi abstrak yang ada dalam diri manusia (Wajdi 2020). Seseorang yang menjalankan fungsi kepemimpinan setidaknya harus memiliki setidaknya persyaratan atau sifat-sifat seperti; 1) bertakwa terhadap Tuhan Yang Maha Esa; 2) memiliki intelegensi yang tinggi, berpengetahuan luas, baik teoritis maupun praktis; 3) memiliki fisik yang kuat, percaya diri, dapat menjadi anggota kelompok, adil dan bijaksana, tegas dan berinisiatif, berkapasitas membuat keputusan; dan 4) memiliki kestabilan emosi, sehat jasmani dan rohani, bersifat prosfektif (Danim 2012). Memimpin adalah bagaimana kita memotivasi, menginspirasi, membawa orang lain ke tingkat yang lebih tinggi, bekerja sama dengan anak buah untuk mencari solusi dari sebuah problem, mendorong mereka meraih prestasi yang lebih tinggi, mengedepankan sikap membimbing daripada memerintah, dan bagaimana seorang pemimpin berjalan bersama anak-anak buahnya (Peters, T. J. 1985). Kepemimpinan mampu memfasilitasi inovasi (Domínguez Escrig et al. 2016). Efektivitas seorang pemimpin ditentukan oleh kepiawaiannya mempengaruhi dan mengarahkan para anggotanya. Pemimpin dapat mempengaruhi semangat dan kegairahan kerja, keamanan, kualitas kehidupan kerja dan juga tingkat prestasi suatu organisasi. Salah satu faktor penting yang mempengaruhi keberhasilan proses kepemimpinan adalah perilaku pemimpin yang bersangkutan atau gaya pemimpin (Fitriani 2015). Kepemimpinan merupakan proses mempengaruhi atau memberi contoh oleh pemimpin kepada bawahannya dalam upaya mencapai tujuan organisasi (Siagian and Wasiman 2020). Dalam konteks negara Indonesia, seorang pemimpin dalam menjalankan kepemimpinannya harus mampu memiliki kecakapan menyelami, menghubungi, 
mempengaruhi, menyakinkan, serta mengajak para anggota masyarakat melalui dinamika sosialnya mau menghayati dan mengamalkan Pancasila demi terwujudnya masyarakat adil dan makmur berdasarkan Pancasila.

Berdasarkan uraian tersebut, maka sangatlah jelas bahwa kepemimpinan merupakan salah satu konsepsi abstrak yang memiliki nilai dalam proses pembentukan karakter antara seorang pemimpin dalam menjalankan kepemimpinannya dengan orang-orang yang dipimpinnya.

Berdasarkan uraian tersebut, maka bagaimana implementasi nilai-nilai kepemimpinan dalam paradigma pancasila sebagai nilai character building.

\section{METODE}

Penelitian ini dilakukan pada mahasiswa USN Kolaka program studi PPKn angkatan 2018. Adapun jenis data adalah data primer dan data sekunder. Sedangkan teknik pengambilan data dilakukan dengan wawancara dan analisis dokumen. Subjek penelitian adalah mahasiswa program studi PPKn angkatan 2018 yang terdiri dari 17 (tujuhbelas) orang mahasiswa. Penelitian menggunakan jenis kualitatif deskriptif dan studi pustaka dengan menerapkan teknik observasi, dokumentasi dan wawancara. Teknik anlisis data dilakukan dengan cara mengkategorikan dan mengklasifikasikan berdasarkan analisis secara logis, kemudian ditafsirkan dalam konteks keseluruhan masalah penelitian. kemudian ditafsirkan dalam konteks keseluruhan masalah penelitian. Metode penelitian kualitatif merupakan metode penelitian yang berlandaskan pada filsafat positivisme (Sugiyono 2016).

\section{implementasi Nilai-nilai Kepemimpinan}

\section{HASIL DAN PEMBAHASAN}

Mahasiswa sebagai peserta didik yang merupakan aset bangsa, dalam perjalanan pendidikannya harus dibekali serta ditanamkan nilai-nilai kepemimpinan yang berlandaskan nilai-nilai Pancasila sebagai hasil kristalisasi nilai budaya, nilai agama, dan nilai kebangsaan Indonesia. Berdasarkan pengamatan peneliti, maka hasil penelitian menunjukkan masih minimnya pengetahuan mahasiswa mengenai nilai-nilai kepemimpinan.

\section{Tabel 1. Pemahaman Nilai-nilai Kepemimpinan}

\begin{tabular}{|l|l|l|l|}
\hline Nama & \multirow{2}{*}{ Mahasiswa } & Jenis Kelamin & Memahami \\
\cline { 3 - 4 } & Laki-laki & & Ta \\
\hline Sar & Laki-laki & $\sqrt{ }$ & \\
\hline Ek & Perempuan & $\sqrt{ }$ & \\
\hline $\mathrm{Ra}$ & Perempuan & $\sqrt{ }$ & \\
\hline $\mathrm{Ma}$ & Perempuan & & $\sqrt{ }$ \\
\hline $\mathrm{Nir}$ & Perempuan & & $\sqrt{ }$ \\
\hline $\mathrm{Ha}$ & Perempuan & & $\sqrt{ }$ \\
\hline $\mathrm{Si}$ & Perempuan & & $\sqrt{ }$ \\
\hline $\mathrm{Km}$ & Perempuan & & $\sqrt{ }$ \\
\hline $\mathrm{Wi}$ & Perempuan & & $\sqrt{ }$ \\
\hline $\mathrm{Mis}$ & Perempuan & & $\sqrt{ }$ \\
\hline $\mathrm{Ag}$ & Perempuan & & $\sqrt{ }$ \\
\hline $\mathrm{Hs}$ & Perempuan & & $\sqrt{ }$ \\
\hline $\mathrm{Es}$ & Perempuan & $\sqrt{ }$ \\
\hline $\mathrm{Ys}$ & Perempuan & $\sqrt{ }$ & $\sqrt{ }$ \\
\hline $\mathrm{Nu}$ & Perempuan & & $\sqrt{ }$ \\
\hline $\mathrm{Sw}$ & Perempuan & & $\sqrt{ }$ \\
\hline
\end{tabular}


Berdasarkan tabel 1 tersebut, maka dari 17 (tujuhbelas) orang mahasiswa prodi TA 2018 terdapat 5 (lima) orang mahasiswa yang sedikit memahami tentang nilai-nilai kepemimpinan, sedangkan 12 (duabelas) orang mahasiswa tidak (belum) memahami tentang nilai-nilai kepemimpinan. Oleh karena itu, ketua program studi PPKn membentuk sebuah organisasi (himpunan) mahasiswa yang disebut HMPS. Dengan adanya kegiatan himpunan mahasiswa program studi (HMPS) tersebut, para mahasiswa diberikan pelatihan dasar kepemimpinan. Dengan adanya pelatihan mahasiswa diharapkan mampu mengimplementasikan dalam dirinya masing-masing sebagai bekalnya nanti ketika berinteraksi dengan masyarakat secara luas baik dalam maupun luar negeri. Tentunya nilai-nilai kepemimpinan tersebut berlandaskan nilai-nilai Pancasila.

\section{Pancasila sebagai Nilai Character Building}

Setelah terbentuknya organisasi himpunan mahasiswa program studi (HMPS). Dalam acara pelatihan, mahasiswa diberikan pembekalan tentang dasar-dasar kepemimpinan. Pembentukan karakter (character building) mahasiswa dilatih dalam acara tersebut. Dan dijelaskan bahwa, seorang pemimpin menjalankan kepemimpinannya harus mengerti, memahami, serta mengaplikasikan nilai-nilai pancasila dalam kepemimpinannya.

Tabel 2. Implementasi Nilai-nilai Kepemimpinan

\begin{tabular}{|c|c|c|c|}
\hline $\begin{array}{l}\text { Nilai-nilai } \\
\text { Kepemimpinan }\end{array}$ & $\begin{array}{l}\text { Nilai-nilai } \\
\text { Pancasila }\end{array}$ & $\begin{array}{l}\text { Character } \\
\text { Building }\end{array}$ & Implementasi \\
\hline $\begin{array}{l}\text { Memotivasi Diri; } \\
\text { Kemampuan } \\
\text { Berbicara di } \\
\text { muka Umum; } \\
\text { Pemahaman } \\
\text { Teknik/Alat } \\
\text { Kendali Mutu; } \\
\text { Kemampuan } \\
\text { memecahkan } \\
\text { masalah; } \\
\text { memotivasi } \\
\text { bawahan; } \\
\text { Mengenali } \\
\text { karakteristik } \\
\text { Bawahan; } \\
\text { Keinginan } \\
\text { mengetahui } \\
\text { perkembangan; } \\
\text { Keinginan } \\
\text { Melakukan } \\
\text { Perubahan; } \\
\text { Sikap Mental; } \\
\text { Citra Diri. }\end{array}$ & $\begin{array}{l}\text { Nilai Ketuhanan; } \\
\text { Nilai } \\
\text { Kemanusiaan; } \\
\text { Nilai Persatuan; } \\
\text { Nilai } \\
\text { Kerakyatan; } \\
\text { Nilai Keadilan }\end{array}$ & $\begin{array}{l}\text { Religius; } \\
\text { Toleransi; } \\
\text { Jujur; Disiplin; } \\
\text { Nasionalis; } \\
\text { Cinta Damai; } \\
\text { Semangat } \\
\text { Kebangsaan; } \\
\text { Gotong } \\
\text { Royong; } \\
\text { Tanggung } \\
\text { Jawab }\end{array}$ & $\begin{array}{l}\text { Nilai Ketuhanan: di dalamnya } \\
\text { terkandung nilai-nilai bahwa } \\
\text { NKRI bukan sebagai negara } \\
\text { agama dan bukan pula sebagai } \\
\text { negara sekuler, tetapi NKRI } \\
\text { ingin dikembangkan sebagai } \\
\text { negara beragama; } \\
\text { Nilai Kemanusiaan: di } \\
\text { dalamnya terkandung nilai-nilai } \\
\text { bahwa NKRI merupakan } \\
\text { negara berdasarkan hak asasi } \\
\text { manusia (berkemanusiaan), } \\
\text { berdasarkan hukum (yang } \\
\text { berkeadilan) dan negara } \\
\text { berbudaya (yang beradab); } \\
\text { Nilai Persatuan: di dalamnya } \\
\text { terkandung nilai-nilai bahwa } \\
\text { NKRI menyatakan diri sebagai } \\
\text { negara yang diikat oleh } \\
\text { persatuan dan kesatuan; } \\
\text { Nilai Kerakyatan yang } \\
\text { dipimpin oleh hikmat dalam } \\
\text { permusyawaratan/perwakilan: } \\
\text { di dalamnya terkadung makna } \\
\text { bahwa NKRI menerapkan asas } \\
\text { kerakyatan yang landasan } \\
\text { penerapannya berdasarkan } \\
\text { kedaulatan rakyat; } \\
\text { Nilai Keadilan Sosial Bagi } \\
\text { seluruh Rakyat Indonesia: di } \\
\text { dalamnya terkandung makna } \\
\text { bahwa keadilan sosial atau }\end{array}$ \\
\hline
\end{tabular}




\begin{tabular}{|l|l|l|}
\hline & & $\begin{array}{l}\text { pemerataan bersama bagi } \\
\text { seluruh komponen rakyat } \\
\text { Indonesia bukan keadilan bagi } \\
\text { segolongan/ } \\
\text { pemerintah/penguasa. }\end{array}$ \\
\hline
\end{tabular}

Berdasarkan tabel 2 tersebut, maka implementasi nilai-nilai kepemimpinan memiliki kaitan dengan nilai-nilai Pancasila dan nilai-nilai character building. (Sutiman 1997), bagi suatu organisasi yang ingin memperoleh kemajuan dalam bidang usahanya, maka kepemimpinan yang baik mutlak dibutuhkan bagi organisasi itu terutama keahlian dalam bidang tersebut, agar: 1) Menghindarkan keputusankeputusan yang bersifat untung-untungan/spekulatif, sehingga dapat diputuskan lebih terarah; 2) Mengindarkan pengambilan keputusan yang tergesa-gesa; dan 3) Menggunakan tenaga kerja dan alat produksi yang dimiliki organisasi secara efektif dan efisien. (Masrukhin 2013), kehidupan bermasyarakat, berbangsa, dan bernegara telah menunjukkan adanya degradasi atau demoralisasi dalam pembentukan karakter dan kepribadian bangsa Indonesia. Degradasi nilai-nilai dan moral sebagai inti (core values) dari pembentukan karakter tidak saja terjadi di kalangan masyarakat awam tetapi juga sudah merambah ke kepribadian para profesional, tokoh masyarakat, para terpelajar, para pendidik, elite politik, bahkan hingga para pemimpin bangsa dan negara.

Kepemimpinan di Indonesia, khususnya kepemimpinan organisasi yang dipimpin oleh seorang pimpinan dalam mempengaruhi situasi kegiatan sosial-budayapendidikan-ekonomi, dan sebagainya sangatlah memegang peranan yang sangat penting. Sebagian besar proses pencapaian tujuan organisasi akan ditentukan oleh kemampuan kepemimpinan yang memegang peranan penting dalam menggerakkan orang-orang pada suatu tujuan tertentu. Manusia Indonesia ideal adalah manusia yang pandangan hidupnya dituntun oleh nilai-nilai Pancasila. Oleh karenanya, pemimpin yang ideal pun semestinya pemimpin yang memiliki karakter Pancasila. (Subagja 2016), manusia mengawali proses kepemimpinannya mulai dari dirinya sendiri. Kesuksesan ia dalam memimpin dirinya dari berbagai problematika dan kompetensi yang terdapat pada dirinya, sangat mempengaruhi pada proses kepemimpinan berikutnya. Di mana ruang lingkup dan jangkauan serta problematika kepemimpinanya jauh lebih luas dan bersifat kompleks (kepemimpinan dalam tataran makro).

Menurut (Gunawan 2016), kepemimpinan Pancasila berarti kepemimpinan yang mengacu kepada sila-sila Pancasila. Seorang pemimpin yang berjiwa Pancasila selalu berupaya menerapkan fungsi kepemimpinannya dengan berlandaskan pada nilai-nilai Pancasila yang diterapkan dan diinternalisasi kepada segenap bawahannya. Nilai-nilai Pancasila menjadi parameter dalam berperilaku setiap warga negara. Nilainilai Pancasila menjadi seperangkat moral dan etika bermasyarakat, berbangsa, dan bernegara. (Kariyadi and Suprapto 2017), pemimpin organisasi di Indonesia apapun jenisnya harus dilandasi pada nilai-nilai pancasila sebagai landasan falsafah negara. (Putra 2018), Pancasila memiliki kedudukan sebagai dasar negara dan ideologi nasional. (Yudi Latief, Adi Suryanto 2015), nasionalisme Pancasila adalah pandangan atau paham kecintaan manusia Indonesia terhadap bangsa dan tanah airnya yang didasarkan pada nilai-nilai Pancasila. Prinsip nasionalisme bangsa Indonesia dilandasi nilai-nilai Pancasila yang diarahkan agar bangsa Indonesia senantiasa: menempatkan persatuan kesatuan, kepentingan dan keselamatan bangsa dan negara di atas kepentingan pribadi atau kepentingan golongan; menunjukkan sikap rela berkorban demi kepentingan bangsa dan negara; bangga sebagai bangsa Indonesia dan bertanah air Indonesia serta tidak merasa rendah diri; mengakui persamaan derajat, persamaan hak dan kewajiban antara sesama manusia dan sesama bangsa; menumbuhkan sikap saling mencintai sesama manusia; mengembangkan sikap 
tenggang rasa. (Alamsyah 2009), terimplementasinya secara baik nilai-nilai Pancasila, akan mengukuhkan dengan tegas arah pencapaian cita-cita dan tujuan nasional secara berkesinambungan dalam kehidupan yang senantiasa dinamis dan mengalami berbagai modifikasi dalam pencapaiannya melalui perwujudan kepemimpinan nasional yang mantap sebab seluruh proses yang ada dalam pengelolaan negara senantiasa diilhami oleh nilai-nilai pancasila, yang merupakan kerangka nilai yang subtantif dalam kedudukannya sebagai pandangan hidup bagi bangsa Indonesia.

\section{SIMPULAN}

Berdasarkan hasil penelitian dan pembahasan, maka dapat kami simpulkan bahwa, mahasiswa Program Studi PPKn USN Kolaka angkatan 2018 sebagaimana pengamatan peneliti menunjukkan masih minimnya pengetahuan mahasiswa mengenai nilai-nilai kepemimpinan dengan jumlah sampel 17 (tujuhbelas) orang mahasiswa, terdapat 5 (lima) orang mahasiswa yang sedikit memahami tentang nilainilai kepemimpinan, sedangkan 12 (duabelas) orang mahasiswa tidak (belum) memahami tentang nilai-nilai kepemimpinan. Dalam implementasi nilai-nilai kepemimpinan yang berlandaskan nilai-nilai Pancasila sebagai hasil kristalisasi nilai budaya, nilai agama, dan nilai kebangsaan Indonesia serta dalam menjalankan kepemimpinannya harus mengerti, memahami dan mengaplikasikan nilai-nilai Pancasila dalam kepemimpinanya.

\section{DAFTAR PUSTAKA}

Alamsyah, M.Nur. (2009). "Eksistensi Nilai-Nilai Filosofi Kebangsaan Dalam Kepemimpinan Nasional." Academica l: 16-34.

Danim, S. (2012). Educational Leadership Genius Leadership (IQ+ EQ) Ethics, Motivational Behavior and Myth. Bandung: Alfabeta.

Dewantara, Ki Hadjar. (2013). Ki Hadjar Dewantara: Pendidikan Pemikiran, Konsepsi, Keteladanan, Sikap Merdeka I (Pendidikan). Yogyakarta: Majelis Luhur Persatuan Tamansiswa.

Domínguez Escrig, Emilio, Francisco Fermín Mallén Broch, Ricardo Chiva Gómez, and Rafael Lapiedra Alcamí. (2016). "How Does Altruistic Leader Behavior Foster Radical Innovation? The Mediating Effect of Organizational Learning Capability." Leadership and Organization Development Journal 37 (8): 105682. https://doi.org/10.1108/LODJ-03-2015-0050.

F. Wajdi, Z. Putra. (2021). "Penguatan Pendidikan Karakter Melalui Nilai Kearifan Lokal Etnis Bajo Dalam Satuan Pendidikan." In Prosiding Simposium Nasional Filsafat Nusantara Ke-1 (Eksplorasi Kekayaan Filsafat Dan Kearifan Lokal Nusantara Dalam Rangka Mewujudkan Indonesia Maju), edited by Heri Santoso, 63-77. Yogyakarta: Laboratorium Filsafat Nusantara Universitas Gadjah Mada.

Fitriani, Annisa. (2015). "Gaya Kepemimpinan Perempuan.” Jurnal TAPIs 11 (2): 24.

Gunawan, Imam. (2016). "Merevitalisasi Kepemimpinan Pancasila Dalam Bidang Pendidikan." In In Prosiding Seminar Nasional Penguatan Manajemen Pendidikan Di Era Kompetisi Global, 67-84. Malang: Jurusan Administrasi Pendidikan Universitas Negeri Malang.

Indonesia, Presiden Republik. 1979. Keputusan Presiden Republik Indonesia Nomor 10 Tahun 1979 Tentang Badan Pembinaan Pendidikan Pelaksanaan Pedoman Penghayatan dan Pengamalan Pancasila., issued 1979.

Kariyadi, Dodi, and Wasis Suprapto. (2017). "Membangun Kepemimpinan Berbasis Nilai-Nilai Pancasila Dalam Perspektif Masyarakat Multikultural." Citizenship Jurnal Pancasila Dan Kewarganegaraan 5 (2): 86. https://doi.org/10.25273/citizenship.v5i2.1560.

Masrukhin, Agus. (2013). "Model Pembelajaran Character Building Dan Implikasinya Terhadap Perilaku Mahasiswa." Humaniora 4 (2): 29-36. 
https://doi.org/10.21512/humaniora.v4i2.3566.

Peters, T. J., \& N. Austin. (1985). A Passion for Excellence: The Leadership Difference. New York: Random House.

Putra, Zulfikar. (2018). "Implementasi Pendidikan Pancasila Sebagai Character Building Mahasiswa Di Universitas Sembilanbelas November Kolaka." Jurnal Citizenship: Media Publikasi Pendidikan Pancasila Dan Kewarganegaraan 1 (1): 9-13.

Siagian, Mauli, and Wasiman. (2020). "Model Hubungan Kepemimpinan, Stres Kerja, Komitmen Kepuasan Kerja Sebagai Variabel Intervening Perusahaan Jasa Pengiriman Kargo Di Kota Batam." Jurnal Rekaman 4 (2).

Subagja, Soleh. (2016). "Paradigma Nilai-Nilai Kepemimpinan Profetik (Spirit Implementasi Model Kepemimpinan Di Lembaga Pendidikan Islam)." Progresiva: Jurnal Pemikiran Dan Pendidikan Islam 3 (2): 23-42. https://doi.org/10.22219/progresiva.v3i2.2062.

Sugiyono. (2016). Metode Penelitian Pendidikan (Pendekatan Kuantitatif, Kualitatif Dan $R \& D)$. Bandung: Alfabeta.

Sutiman, A. H. 1997. "Apa Dan Bagaimanakah Kepemimpinan Pancasila Itu?" Majalah Komunikasi Maranatha 4 (4).

Wajdi, Farid. (2020). Nilai-Nilai Karakter Etnis Bajo Relevan Dengan Nilai Karakter Bangsa. Makassar: Yayasan Barcode.

Yudi Latief, Adi Suryanto, Abdul Aziz Muslim. (2015). NASIONALISME: Modul Pendidikan Dan Pelatihan Prajabatan Golongan III. Jakarta: Lembaga Administrasi Negara.

Z. Putra, F. Wajdi. (2021). Buku Ajar Pendidikan Pancasila Dan Kewarganegaraan Panduan Kuliah Di Perguruan Tinggi. Malang: Ahlimedia Press. 